\title{
Prevalence of Intestinal Parasitic Infection among HIV Positive Persons Who Are Naive and on Antiretroviral Treatment in Hiwot Fana Specialized University Hospital, Eastern Ethiopia
}

\author{
Zelalem Teklemariam, ${ }^{1}$ Degu Abate, ${ }^{1}$ Habtamu Mitiku, ${ }^{1}$ and Yadeta Dessie ${ }^{2}$ \\ ${ }^{1}$ Department of Medical Laboratory Sciences, College of Health and Medical Sciences, Haramaya University, \\ P.O. Box 235, Harar, Ethiopia \\ ${ }^{2}$ Department of Public Health, College of Health and Medical Sciences, Haramaya University, P.O. Box 235, Harar, Ethiopia
}

Correspondence should be addressed to Zelalem Teklemariam; zelalemtmariam@yahoo.com

Received 23 April 2013; Accepted 20 May 2013

Academic Editors: D. Aunis, H. C. Mwandumba, C. Petrovas, and J. Poudrier

Copyright (c) 2013 Zelalem Teklemariam et al. This is an open access article distributed under the Creative Commons Attribution License, which permits unrestricted use, distribution, and reproduction in any medium, provided the original work is properly cited.

\begin{abstract}
Background. Intestinal parasitic infection affects the health and quality of life of people living with HIV. This study was aimed to determine the prevalence of intestinal parasites among HIV positive individuals who are naive and who are on antiretroviral treatment (ART) in Hiwot Fana Specialized University Hospital, Eastern Ethiopia. Methods. A comparative cross-sectional study was conducted on 371 (112 ART-naive group and 259 on ART) HIV positive individuals. Stool specimens were collected and examined by direct wet mount, formol ether concentration technique, and modified ziehl-Neelsen methods. Results. The overall prevalence of intestinal parasitic infections was 33.7\%; it was significantly higher among the study participants who were ARTnaive group (45.5\%) (AOR: 2.60(1.56,4.34)) and diarrheic (53.3\%) (AOR: $2.30(1.34,3.96)$ ) and with $\mathrm{CD}_{4}$ count $<200$ cells/ $\mu \mathrm{L}(46 \%)$ (AOR: 2.07(1.06,4.04)). The most commonly identified parasites were Entamoeba histolytica/E. dispar (13.5\%), Giardia lamblia (8.1\%), Strongyloides stercoralis (4.0\%), and Cryptosporidium species (2.2\%). Conclusion. HIV positive individuals with diarrhea and low $\mathrm{CD}_{4}$ count and ART naive groups were more infected with intestinal parasites than their counterparts. Early stool examination and treatment of intestinal parasites for HIV/AIDS patients is essential.
\end{abstract}

\section{Introduction}

Globally about 3.5 billion people are infected with intestinal parasite. Out of whom, 450 million are suffering from its illness $[1,2]$. The prevalence of intestinal parasitic infection is high in Sub-Saharan Africa, where the majority of HIV/AIDS cases are from $[2,3]$. Parasites are common infections among HIV/AIDS patients [4-7]. Diarrhea causing opportunistic parasites like Cryptosporidium parvum and Isospora belli is common among HIV positive persons with $\mathrm{CD}_{4}$ count less than 200 cells $/ \mu \mathrm{L}[4,5]$.

Antiretroviral treatment (ART) increases the length and quality of life and productivity of patients by improving survival and decreasing the incidence of opportunistic infections in people with HIV through reduction of the viral load and increasing the level of $\mathrm{CD}_{4}$ cells [8]. Nevertheless, in Ethiopia, few studies have tried to investigate the extent of intestinal parasitic infections in relation to ART experiences and CD4 count $[4,5]$.

Therefore, we investigated the prevalence of intestinal parasites among HIV positive persons who were naive and who were on ART in Hiwot Fana Specialized University Hospital, Eastern Ethiopia.

\section{Material and Methods}

2.1. Study Setting. The study was conducted in Hiwot Fana Specialized University Hospital, Harar, Ethiopia. It is a teaching hospital of Haramaya University. The hospital is found in Harari National Regional State which is one of the Federal Democratic Republic of Ethiopia regional states located $515 \mathrm{~km}$ from Addis Ababa. In Harar, there are six hospitals and eight health centers. The health service coverage 
of the region was estimated to be above $100 \%$. A comparative cross-sectional study was conducted among Naive and on ART HIV positive persons in Hiwot Fana Specialized University Hospital from March to April, 2011.

2.2. Study Participant. The study population was all the HIV positive individuals who were on ART and pre ART care in the ART unit of the hospital during the study period. Individuals who were on parasitic treatments during the data collection period were excluded. The prevalence of intestinal parasites among ART-naive group HIV positive individuals was taken as $50 \%$ and to detect a difference of $15 \%$ between the two groups with the assumption of $95 \%$ confidence level (CL), power of $80 \%(0.84)$ and ratio $2: 1$ of those on ART and ART-naive group. Double proportion formula was applied to calculate the sample size which was 274 on ART and 137 ART-naive group. A 5\% nonresponse rate was added and the final calculated sample size was 431 . Study participants were selected by simple random sampling techniques.

\subsection{Data Collection and Laboratory Investigation Procedures}

2.3.1. Stool Collection and Examination. Small pieces of labeled clean plastic sheets and wooden applicator sticks were distributed and the participants were instructed to bring sizable stool specimen of their own. With the provision of specimen, each participant was interviewed for sociodemographic variables. Each stool specimen was initially assessed for consistency. Then, it was examined by direct wet mount method using normal saline $(0.85 \% \mathrm{NaCl}$ solution $)$ at Hiwot Fana Specialized University Hospital Laboratory in order to prevent the loss of motile stage of parasites. Lugol's iodine was used to detect the cyst of intestinal parasites. The remaining sample was preserved with $10 \%$ formalin and transported to the laboratory of Medical Laboratory Sciences Department Haramaya University. In the laboratory, it was examined by formol ether concentration technique and modified Zeihl-Neelsen method (for detection of opportunistic parasites-Cryptosporidium species, Cyclospora cayetanensis, and Isospora belli) [9]. The most recent $\mathrm{CD}_{4}$ T-cells counts of the participants were obtained from their ART fellow-up record in the hospital.

2.4. Data Processing and Analysis. Data were entered into Epideta Version 3.1 and transported to SPSS Version 16 software for analysis. The prevalence of intestinal parasites was determined in relation to different variables Pearson's chi square test was used to assess statistical significance difference between proportions. Bivariate and multivariate analyses were performed to assess crude and adjusted ratio. A statistical test result was reported as significant when its $P$ value was less than 0.05 .

2.5. Ethical Consideration. Ethical clearance was obtained from Haramaya University Colleges of Health and Medical Sciences Institutional Research and Ethical Review Committee. All the participants were explained about the purpose and their right to participate or not to participate in this study.
Those who gave their written consent participated in this study. Moreover, all personal information of the participants was kept confidential. Those participants who were found positive for intestinal parasitic infection were treated free of charge using the standard drugs by nurses in ART unit. ART follow-up record was also retrieved by nurses working in ART unit.

\section{Results}

3.1. Sociodemographic Characteristics of Study Participants. A total of 259 on ART and 112 ART-naive group HIV positive clients participated in the study, and the response rate was $86.7 \%$. The mean age of the participants was 33.6 (SD \pm 10.04 ) and many of the ART-naive group (68.5\%) and on ART (70\%) participants were female. The majority of the study subjects were in the age group of 25-34, married, daily laborers, and urban dwellers (Table 1).

3.2. The Distribution of Parasite Species. The overall prevalence of intestinal parasites among the study participants was $33.7 \%$ (125/371). It was significantly higher in the ARTnaive group $(45.5 \%(51 / 112))$ compared to those on ART (28.6\% (74/259)) $(P=0.002)$. Some were infected with nonopportunistic $(31.8 \%)$ and very few with opportunistic (3.5\%) parasites.

Eleven parasite species were detected: Entamoeba histolytica/Entamoeba dispar (13.4\% on ART-naive group and $13.5 \%$ on ART group $(P>0.05))$ and Giardia lamblia (7.1\% on ART-naive group and $8.5 \%$ on ART group) were the common ones. Opportunistic parasites like Crypotospriudum (7.1\%) and Isospora belli (4.5\%) were found only in ART-naive group group.

Some of the ART-naive group (26.8\%) and few of the on ART $(17.4 \%)$ subjects were diarrheic $(P<0.05)$; most of them were infected with $G$. lamblia $(P>0.05)$, Crypotospriudum species, I. belli, and S. Stercolaris. The overall prevalence of intestinal parasites was significantly higher among diarrheic $(53.3 \%(40 / 75))$ as compared to nondiarrheic $(28.7 \%$ $(85 / 296))$ study participants $(P<0.05)$ (Table 2$)$.

About 31\% (31/100), 17.3\% (34/196), and 13.3\% (10/75) of the study participants with $\mathrm{CD}_{4}$ count less than 200 cells $/ \mu \mathrm{L}$, $200-499$ cells $/ \mu \mathrm{L}$ and greater than or equal to 500 cells $/ \mu \mathrm{L}$, respectively, were diarrheic. The prevalence of diarrhea is significant in participants with $\mathrm{CD}_{4}$ count less than 200 cells $/ \mu \mathrm{L}$ $(P=0.005)$.

In the bivariate analysis, age, sex, occupation, residence, education, and marital status of the participants did not show significant association with prevalence of intestinal parasites. Participants with $\mathrm{CD}_{4}$ count less than 200 cells/ $\mu \mathrm{L}$ (COR: 1.93; CI: 1.03, 3.61), diarrheic (COR: 2.84; CI: 1.69, 4.77), and ART-naive group (COR: 2.09; CI: 1.32, 3.31) had higher risk of intestinal parasites. The participants with $\mathrm{CD}_{4}$ count $<$ 200 cells/ $\mu \mathrm{L}$ were 2.07 times more likely to be infected with intestinal parasites than those with $\mathrm{CD}_{4}$ count $\geq 500$ cells $/ \mu \mathrm{L}$. The diarrheic participants and the ART-naive group ones were 2.30 and 2.60 times more likely to be infected with intestinal parasites (Table 3 ). 
TABLE 1: Sociodemographic characteristics of naïve ART and on ART HIV positive study participants at Hiwot Fana Specialized University Hospital, Harar, Eastern Ethiopia, 2011.

\begin{tabular}{|c|c|c|c|}
\hline Variables & $\begin{array}{c}\text { Naïve ART } \\
N(\%)\end{array}$ & $\begin{array}{c}\text { On ART } \\
N(\%)\end{array}$ & $\begin{array}{c}\text { Total } \\
N(\%)\end{array}$ \\
\hline \multicolumn{4}{|l|}{ Age (in year) } \\
\hline $15-24$ & $35(31.5 \%)$ & $40(15.6 \%)$ & $75(20.4)$ \\
\hline $25-34$ & $51(45.9 \%)$ & $121(47.3 \%)$ & $172(46.9)$ \\
\hline$\geq 35$ & $25(22.5 \%)$ & $95(37.1 \%)$ & $120(32.7)$ \\
\hline \multicolumn{4}{|l|}{ Sex } \\
\hline Male & $35(31.5)$ & $76(29.3)$ & $111(30)$ \\
\hline Female & $76(68.5)$ & $183(70.7)$ & $259(70)$ \\
\hline \multicolumn{4}{|l|}{ Educational status } \\
\hline Illiterate & $27(24.1)$ & $56(21.6)$ & $83(22.4)$ \\
\hline Read and write & $3(2.7)$ & $7(2.7)$ & $10(2.7)$ \\
\hline Elementary school & $49(43.8)$ & $94(36.3)$ & $143(38.5)$ \\
\hline High school and above & $33(29.5)$ & $102(39.4)$ & $135(36.4)$ \\
\hline \multicolumn{4}{|l|}{ Marital status } \\
\hline Single & $30(27.5)$ & $56(21.6)$ & $86(23.4)$ \\
\hline Married & $55(50.5)$ & $112(43.2)$ & $167(45.4)$ \\
\hline Divorced & $14(12.8)$ & $55(21.2)$ & $69(18.8)$ \\
\hline Widowed & $10(9.2)$ & $36(13.9)$ & $46(12.5)$ \\
\hline \multicolumn{4}{|l|}{ Occupation } \\
\hline Government employee & $14(12.8)$ & $56(21.8)$ & $70(19.1)$ \\
\hline Nongovernmental organization & $5(4.6)$ & $13(5.1)$ & $18(4.9)$ \\
\hline Farmer & $2(1.8)$ & $11(4.3)$ & $13(3.6)$ \\
\hline Merchants & $23(21.1)$ & $47(18.3)$ & $70(19.1)$ \\
\hline Daily laborer & $27(24.8)$ & $66(25.7)$ & $93(25.4)$ \\
\hline House wife & $19(17.4)$ & $26(10.1)$ & $45(12.3)$ \\
\hline Students & $1(0.9)$ & $3(1.2)$ & $4(1.1)$ \\
\hline Other & $12(11.0)$ & $16(6.2)$ & $28(7.7)$ \\
\hline No job & $6(5.5)$ & $19(7.4)$ & $25(6.8)$ \\
\hline \multicolumn{4}{|l|}{ Residence } \\
\hline Rural & $23(21.3)$ & $65(25.3)$ & $88(24.1)$ \\
\hline Urban & $85(78.7)$ & $192(74.2)$ & $277(75.9)$ \\
\hline
\end{tabular}

TABLE 2: Intestinal parasite species identified with ART and diarrheic status of HIV positive study participants at Hiwot Fana Specialized University Hospital, Harar, Eastern Ethiopia, 2011.

\begin{tabular}{|c|c|c|c|c|c|c|c|}
\hline Parasite species & $\begin{array}{c}\text { Naïve ART } \\
(N=112) \\
\text { Number of pos. } \\
(\%)\end{array}$ & $\begin{array}{c}\text { On ART } \\
(N=259) \\
\text { Number of } \\
\text { pos. }(\%)\end{array}$ & $\begin{array}{c}\text { Total } \\
(N=371) \\
\text { Number of pos. } \\
(\%)\end{array}$ & $P$ value & $\begin{array}{c}\text { Diarrheic } \\
(n=75) \\
\text { Number of } \\
\text { pos. }(\%)\end{array}$ & $\begin{array}{c}\text { Nondiarrheic } \\
(n=296) \\
\text { Number of } \\
\text { pos. }(\%)\end{array}$ & $P$ value \\
\hline Entamoeba histolytica/E. dispar & $15(13.4)$ & $35(13.5)$ & $50(13.5)$ & 0.975 & $10(13.3)$ & $40(13.5)$ & 0.967 \\
\hline Giardia lamblia & $8(7.1)$ & $22(8.5)$ & $30(8.1)$ & 0.661 & $9(12)$ & $21(7.1)$ & 0.164 \\
\hline Strongyloides stercoralis & $6(5.4)$ & $9(3.5)$ & $15(4.0)$ & - & $9(12)$ & $6(2)$ & - \\
\hline Crypotospriudum species & $8(7.1)$ & $0(0)$ & $8(2.2)$ & & $7(9.3)$ & $1(0.3)$ & - \\
\hline Hookworm & $3(2.7)$ & $4(1.5)$ & $7(1.9)$ & - & $0(0)$ & $7(2.4)$ & - \\
\hline Isospora belli & $5(4.5)$ & $0(0)$ & $5(1.3)$ & - & $5(6.7)$ & $0(0)$ & - \\
\hline Hymenolepis nana & $1(0.9)$ & $4(1.5)$ & $5(1.3)$ & - & $0(0)$ & $5(1.7)$ & - \\
\hline Taenia saginata & $0(0)$ & $3(1.2)$ & $3(0.8)$ & - & 0 & $3(1.0)$ & - \\
\hline Ascaris lumbricoides & $2(1.8)$ & $1(0.4)$ & $3(0.8)$ & - & $1(1.3)$ & $2(0.7)$ & - \\
\hline Schistosoma mansoni & $2(1.8)$ & $1(0.4)$ & $3(0.8)$ & - & $1(1.3)$ & $2(0.7)$ & \\
\hline Enterobius vermicularis & $2(1.8)$ & $0(0)$ & $2(0.5)$ & - & $0(0)$ & $2(0.7)$ & - \\
\hline
\end{tabular}


TABLE 3: Associating intestinal parasite with CD4 count and diarrheic and ART status among HIV positive study participants at Hiwot Fana Specialized University Hospital, Eastern Ethiopia, 2011.

\begin{tabular}{|c|c|c|c|c|c|}
\hline Variables & $\begin{array}{l}\text { No examined } \\
\text { (\% pos.) }\end{array}$ & $\begin{array}{c}\text { Crude odds ratio } \\
\text { (95\% confidence } \\
\text { interval) }\end{array}$ & $P$ value & $\begin{array}{l}\text { Adjusted odds ratio } \\
\text { (95\% confidence } \\
\text { interval) }\end{array}$ & $P$ value \\
\hline \multicolumn{6}{|c|}{$\mathrm{CD}_{4}$ count $($ cells $/ \mu \mathrm{L})$} \\
\hline$\geq 500$ & 75 (30.7) & 1 & & 1 & \\
\hline $200-499$ & $196(28.6)$ & $0.90(0.51,1.62)$ & 0.734 & $0.78(0.42,1.42)$ & 0.409 \\
\hline$<200$ & $100(46)$ & $1.93(1.03,3.61)$ & 0.041 & $2.07(1.06,4.04)$ & 0.034 \\
\hline \multicolumn{6}{|l|}{ Diarrheic status } \\
\hline Nondiarrheic & $296(28.7)$ & 1 & & 1 & \\
\hline Diarrheic & $75(53.3)$ & $2.84(1.69,4.77)$ & 0.000 & $2.30(1.34,3.96)$ & 0.003 \\
\hline \multicolumn{6}{|l|}{ ART status } \\
\hline On ART & $259(28.6)$ & 1 & & 1 & \\
\hline Naïve ART & $112(45.5)$ & $2.09(1.32,3.31)$ & 0.002 & $2.60(1.56,4.34)$ & 0.000 \\
\hline
\end{tabular}

\section{Discussions}

Intestinal parasitic infections are the major causes of morbidity and mortality in HIV positive patients $[4-7,10]$. In this study, about $33.7 \%$ of the participants were infected with intestinal parasites. The result is almost similar to the ones reported from Afar, Ethiopia [5], Cameroon [11], and Saudi Arabia [12], but lower than those from Jimma [13], Hawassa [4], Bahir Dar [14], Dire Dawa and Afar [5] of Ethiopia, India [15], Kenya [16], and Jakarta [17]. But it is higher than a finding in Senegal [18]. The difference in the prevalence might be due to differences in geographical location, sensitivity of diagnostic techniques, study participants' immunity status, environmental hygiene, socioeconomic status, access to safe water supply, or other.

Several species of protozoa and other intestinal parasites have been associated with acute and chronic diarrhea and even weight loss in HIV/AIDS patients [19, 20]. In this study, Entamoeba histolytica/E. dispar and Giardia lamblia were the commonest nonopportunistic protozoa. The overall prevalence of Entamoeba histolytica/E. dispar was $13.5 \%$. The finding is similar with $13 \%$ report in Ethiopia [5]. But it is higher than a report in Ethiopia (4.2\%) [14], Saudi Arabia $(5.2 \%)$ [12], and Jakarta (0.3\%) [17]. It is lower than the one in Kenya (58.3\%) [16] and Ethiopia (23.8\%) [13]. The overall prevalence of Gardia lamblia was $8.1 \%$. It is slightly lower than $10.6 \%$ in Ethiopia [13]. However, it is higher than report of $1.1 \%$ in Ethiopia [14], 0.6\% in Senegal, and 1.9\% in Jakarta [17]. It is also lower than report of $16.6 \%$ in Kenya [16] and $16 \%$ in Ethiopia [5].

Opportunistic protozoa like Crypotospriudum species and Isospora belli were also identified in this study. The prevalence of Crypotospriudum species was $2.2 \%$ and this is lower than the findings from other studies which are found in the range of $4.9 \%$ to $15.8 \%[5,12-15,17]$. While Isospora belli was found at $1.3 \%$. This is lower than other studies which are found in the range of $3.9 \%$ to $11.7 \%$ [5, 13-15]. The lower prevalence of both parasites in this study might be due to that our study participants are in the ART care who were taking ART and/or treatment for opportunistic infection. The other reason might be due to difference in immunity, diarrheic status, environmental and personal hygiene of the study participants.

Other nonopportunistic intestinal helimiths were identified at the rate of ranging from $0.5 \%$ to $4.0 \%$. The highest prevalent helminth was Strongyloides stercoralis. This is similar to study carried out in Ethiopia [13], but it is slightly lower than another study in Ethiopia [14] and Saudi Arabia [12]. The effect of Strongyloides Stercolaris in HIV infected patients, which is disseminated strongloidiasis, was reported in another study [21].

In this study, we tried to compare the prevalence of intestinal parasites with the diarrheic status, $\mathrm{CD}_{4}$ count, and ART experience of HIV positive persons. The prevalence of intestinal parasites was significantly higher among diarrheic as compared to nondiarrheic groups. Similar reports are found in other studies $[12,15,16]$. The most common diarrheal causing parasites were E. histolytica, Gardia lamblia, Crypotospriudum species, Isospora belli, and Strongyloides stercoralis. Similarly, there are reports which showed that diarrhea can be caused by opportunistic and nonopportunistic parasites $[5,15,22]$.

The association between opportunistic parasitic infection and HIV is widely reported $[4,15,23]$. However, in this study, most of the parasites identified were nonopportunistic. The relationship between nonopportunistic parasite and HIV was not well established. Even though the defense against them might be damaged by HIV, the exposure to this parasites are likely to occur independent of HIV infection but heavier parasitic load might accumulate as well as experience of delayed clearance of parasite in individual with concurrent HIV induced immunosupperssion [23, 24].

The prevalence of intestinal parasites was highly significant among those study participants with $\mathrm{CD}_{4}$ count $<200$ cells $/ \mu \mathrm{L}$ in this study. This is consistent with other studies $[4,5,15]$. The correlation of $\mathrm{CD}_{4}$ count with opportunistic parasites could not be assessed because of small number of individuals infected with Crypotospriudum species 
and Isospora belli. However, the association of these two parasites with HIV positive persons, who have $\mathrm{CD}_{4}$ count $<200$ cells $/ \mu \mathrm{L}$, is reported in other studies $[4,5,15,23]$

The prevalence of intestinal parasites was significantly higher when ART-naive group compared to those on ART study participants. Opportunistic parasites, which are Crypotospriudum species and Isospora belli, were found only in ART-naive group group. This is similar to study conducted in Ethiopia [5]. ART increases the immunity status HIV positive persons and decreases the incidence of opportunistic infections [8].

The study was not without limitations. The detection method for Microsoporidia was not employed and sensitive diagnostic techniques for Strongyloides stercoralis and Enetrobius vermicularis were not used. Therefore, the prevalence intestinal parasites in our study participant may have been underestimated. HIV negative control groups were not included in this study which was the other limitation.

\section{Conclusions}

The prevalence of intestinal parasite was high. Opportunistic and nonopportunistic parasites were identified with a different rate. The prevalence of intestinal parasites was higher among those HIV infected individuals with diarrhea, low $\mathrm{CD}_{4}$ count, and ART-naive group groups. Those results posit the need for considering early detection and treatment of intestinal parasites in HIV infected individuals in order to reduce their morbidity. This seeks great attention by those clinical service providers who are working in the ART unit. Adherence counseling of ART, health information dissemination on environmental, and personal hygiene should also be given to HIV/AIDS patients. In addition further large scale study by using different diagnostic techniques, HIV negative control and assessing predisposing factors of intestinal parasites is recommended.

\section{Acknowledgments}

The authors acknowledge Haramaya University for funding this research. They also would like to thank all their study participants, data collectors, and supervisors. Hiwot Fana Specialized University Hospital administration is also strongly acknowledged.

\section{References}

[1] World Health Organization (WHO), Control of Tropical Diseases, WHO, Geneva, Switzerland, 1998.

[2] WHO, "Prevention of schistosomiasis and soil transmitted helminthiasis: report of WHO Expert Committee," WHO Technical Report Series 912, WHO, Geneva, Switzerland, 2002.

[3] UNAIDS/WHO, AIDS Epidemic Update, World Health Organization, Geneva, Switzerland, 2006.

[4] S. Assefa, B. Erko, G. Medhin, Z. Assefa, and T. Shimelis, "Intestinal parasitic infections in relation to HIV/AIDS status, diarrhea and $\mathrm{CD}_{4}$ T-cell count," BMC Infectious Diseases, vol. 9, article 155, 2009.
[5] H. Adamu and B. Petros, "Intestinal protozoan infections among HIV positive persons with and without Antiretroviral Treatment (ART) in selected ART centers in Adama, Afar and Dire-Dawa, Ethiopia," The Ethiopian Journal Health Development, vol. 23, no. 2, pp. 133-140, 2009.

[6] A. E. Ibrahim, E. I. Ikeh, A. O. Malu, E. N. Okeke, and J. G. Damen, "Intestinal parasitosis in HIV infected adult with chronic diarrhea at Jos University teaching hospital, Nigeria," Internet Journal of Parasitic Diseases, vol. 2, no. 1, 2007.

[7] S. Kumas and S. Anthania, "Intestinal parasitic infection in HIV infected patients with diarrhea in clinic," Indian Journal of Medical Microbiology, vol. 20, no. 2, pp. 88-91, 2002.

[8] R. S. Hogg, B. Yip, C. Kully et al., "Improved survival among HIV-infected patients after initiation of triple-drug antiretroviral regimens," Canadian Medical Association Journal, vol. 160, no. 5, pp. 659-665, 1999.

[9] M. Cheesbrough, District Laboratory Practice in Tropical Countries Part 1, Cambridge University Press, New York, NY, USA, Second edition, 2009.

[10] S. Gupta, S. Narang, V. Nunavath, and S. Singh, "Chronic diarrhoea in HIV patients: prevalence of coccidian parasites," Indian Journal of Medical Microbiology, vol. 26, no. 2, pp. 172 175, 2008.

[11] C. Sarfati, A. Bourgeois, J. Menotti et al., "Prevalence of intestinal parasites including microsporidia in human immunodeficiency virus-infected adults in Cameroon: a cross-sectional study," The American Journal of Tropical Medicine and Hygiene, vol. 74, no. 1, pp. 162-164, 2006.

[12] W. A. I. Al-Megrin, "Intestinal parasites infection among immunocompromised patients in Riyadh, Saudi Arabia," Pakistan Journal of Biological Sciences, vol. 13, no. 8, pp. 390-394, 2010.

[13] Z. T. Mariam, G. Abebe, and A. Mulu, "Opportunistic and other intestinal parasitic infections in AIDS patients, HIV seropositive healthy carriers and HIV seronegative individuals in Southwest Ethiopia," East African journal of public health, vol. 5, no. 3, pp. 169-173, 2008.

[14] A. Alemu, Y. Shiferaw, G. Getnet, A. Yalew, and Z. Addis, "Opportunistic and other intestinal parasites among HIV/AIDS patients attending Gambi higher clinic in Bahir Dar city, North West Ethiopia," Asian Pacific Journal of Tropical Medicine, vol. 4, no. 8, pp. 661-665, 2011.

[15] R. Naik, H. Ravichandraprakash, P. M. Ukey, V. Vijayanath, G. Shreeharsha, and V. K. Chandak, "Opportunistic intestinal parasitic infections in HIV/AIDS patients presenting with diarrhea and their correlation with CD4+ T-lymphocyte counts," International Journal of Pharmacy and Biological Sciences, vol. 2, no. 4, pp. 293-299, 2012.

[16] C. K. Kipyegen, R. S. Shivairo, and R. O. Odhiambo, "Prevalence of intestinal parasites among HIV patients in Baringo, Kenya," Pan African Medical Journal, vol. 13, article 37, 2012.

[17] A. Kurniawan, T. Karyadi, S. W. Dwintasari et al., "Intestinal parasitic infections in HIV/AIDS patients presenting with diarrhoea in Jakarta, Indonesia," Transactions of the Royal Society of Tropical Medicine and Hygiene, vol. 103, no. 9, pp. 892-898, 2009.

[18] B. Faye, R. C. Tine, J. L. Ndiaye et al., "Impact of intestinal parasites on intensity of HIV infection in senegal," Journal of Antivirals and Antiretrovirals, vol. 2, no. 1, pp. 11-12, 2010.

[19] G. Feitosa, A. C. Bandeira, D. P. Sampaio, R. Badaró, and C. Brites, "High prevalence of giardiasis and stronglyloidiasis 
among HIV-infected patients in Bahia, Brazil," The Brazilian Journal of Infectious Diseases, vol. 5, no. 6, pp. 339-344, 2001.

[20] K. Modjarrad, I. Zulu, D. T. Redden, L. Njobvu, D. O. Freedman, and S. H. Vermund, "Prevalence and predictors of intestinal helminth infections among human immunodeficiency virus type 1-infected adults in an urban African setting," The American Journal of Tropical Medicine and Hygiene, vol. 73, no. 4, pp. 777-782, 2005.

[21] R. Ramanathan and T. B. Nutman, "Strongyloides stercoralis infection in the immunocompromised host," Current Infectious Disease Reports, vol. 10, no. 2, pp. 105-110, 2008.

[22] W. V. Kit, "Intestinal parasitic infections in Thai HIV- infected patients with different immunity status," BMC Gastroenterology, vol. 1, article 3, 2001.

[23] M. Awole, S. Gebre-Selassie, T. Kassa, and G. Kibru, "Prevalence of intestinal parasites in South-Western Ethiopia," The Ethiopian Journal of Health Development, vol. 17, no. 1, pp. 71-78, 2003.

[24] T. Evering and L. M. Weiss, "The immunology of parasite infections in immunocompromised hosts," Parasite Immunology, vol. 28, no. 11, pp. 549-565, 2006. 


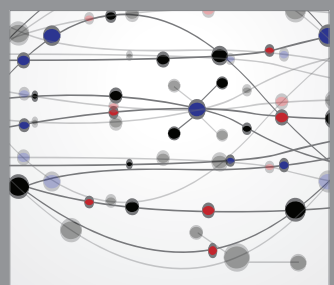

The Scientific World Journal
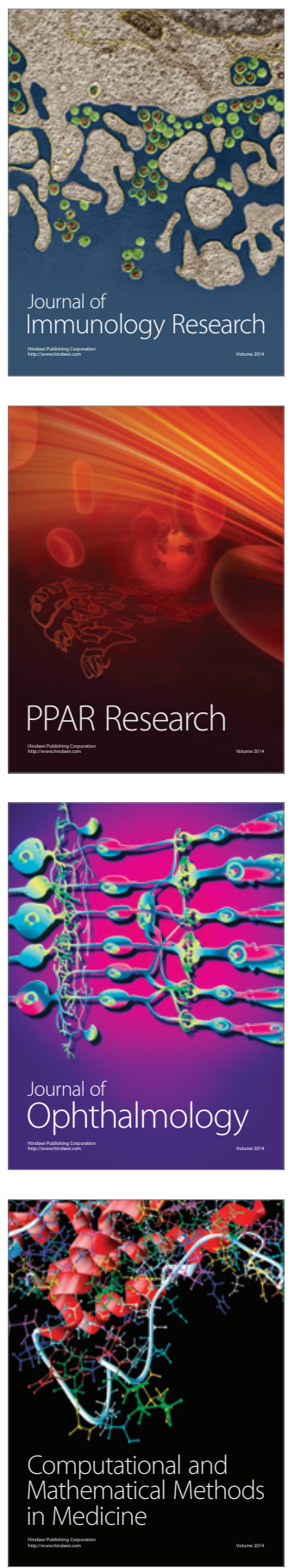

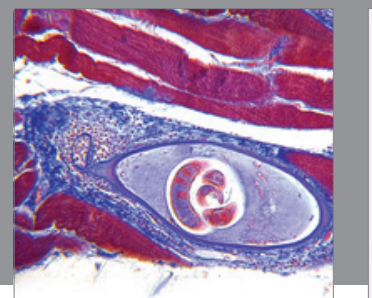

Gastroenterology

Research and Practice
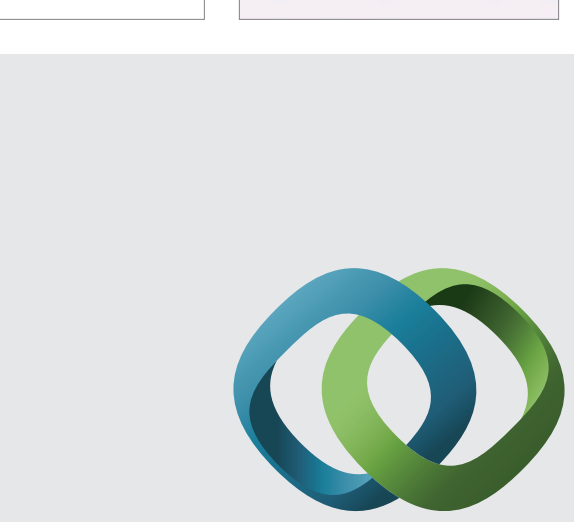

\section{Hindawi}

Submit your manuscripts at

http://www.hindawi.com
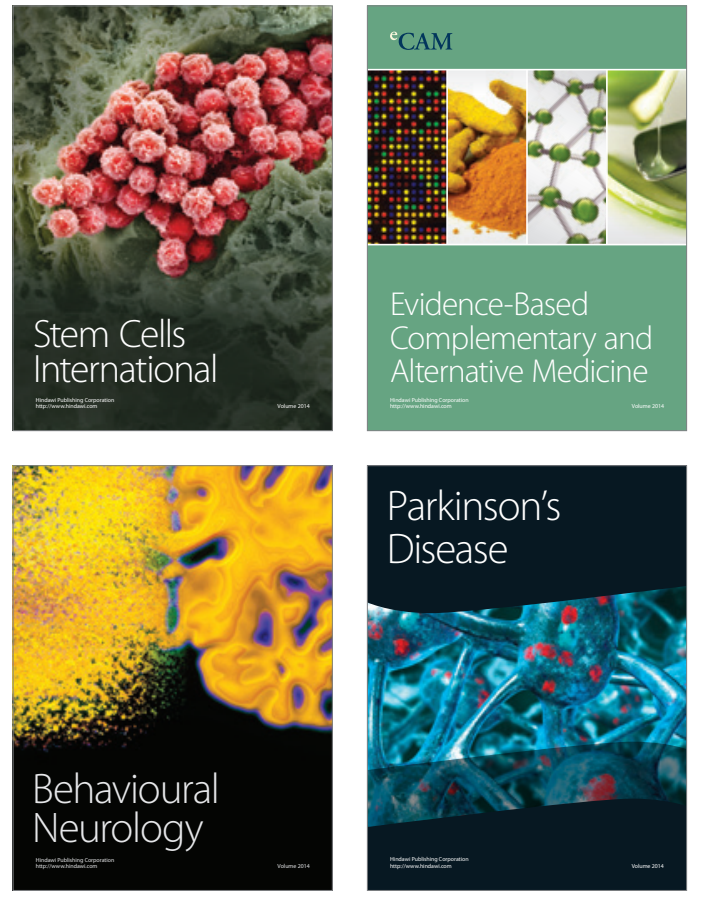
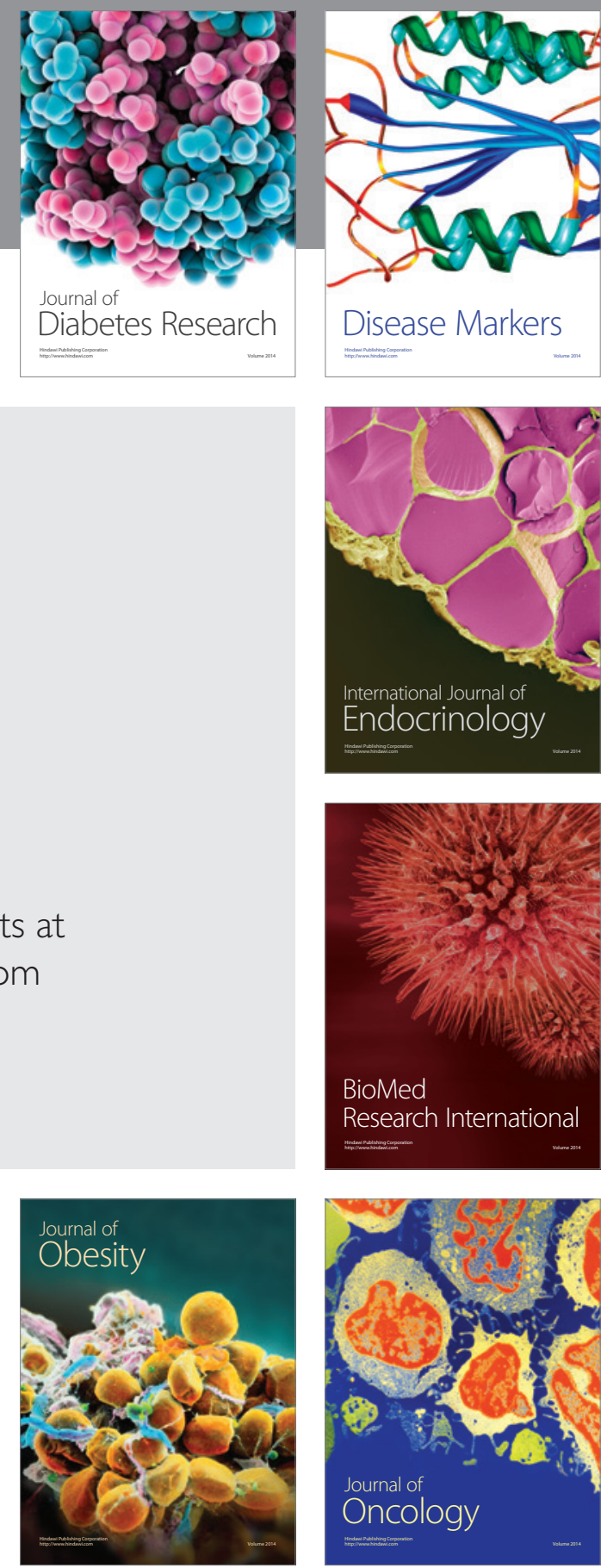

Disease Markers
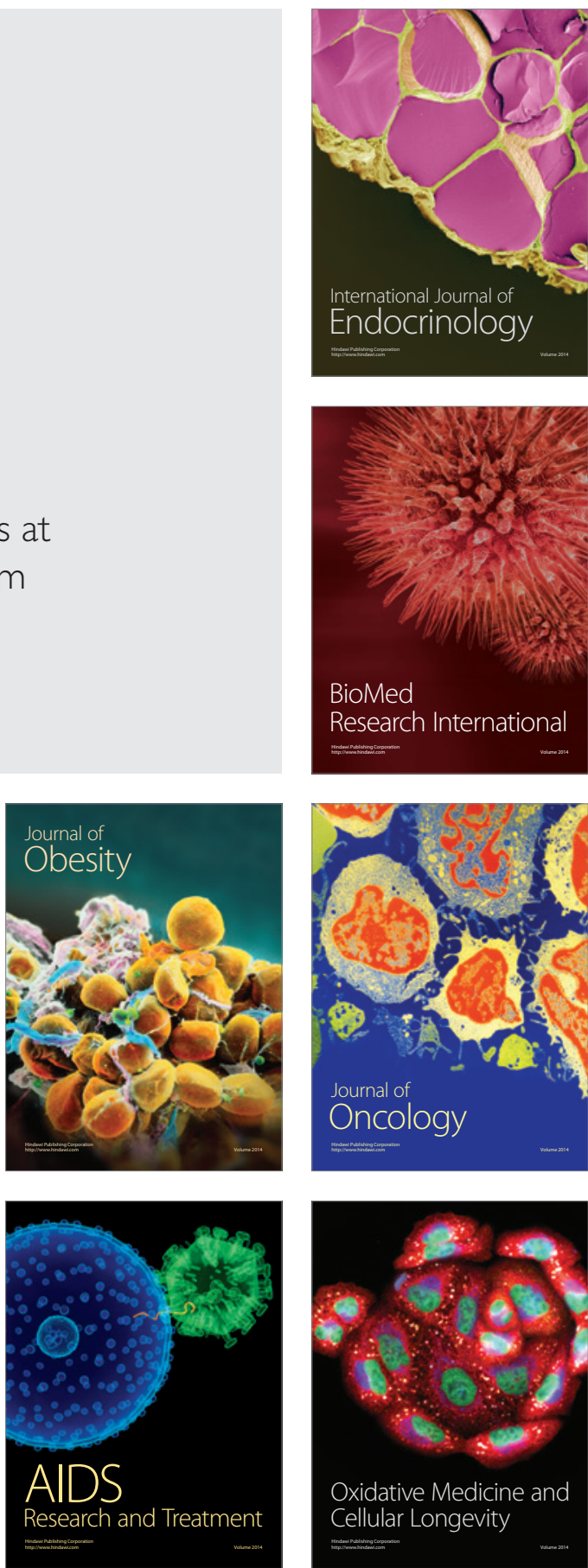